\title{
BMJ Open Quality Increasing postpartum IUCD coverage through a QI initiative: a step towards reducing the unmet need of postpartum contraception
}

Swati Agrawal, Manju Puri, Anuradha Singh, Sushma Sehrawat, Shilpa Sood,
Kavita Choudhary, Anu Handa, R Induja, Apurwa Bardhan, Pooja Luthra,
Preeti Pawar, Nidhi Singh, Swati Tyagi, Jismaria Antony, Priyanka Arora,
Sukriti Ghai, Tanya Shubham, Vaishali Suraiya, Surabhi Sapna, Mani Ajithkumar

ABSTRACT

To cite: Agrawal S, Puri M Singh $A$, et al. Increasing postpartum IUCD coverage through a QI initiative: a step towards reducing the unmet need of postpartum contraception. BMJ Open Quality 2021;10:e001346. doi:10.1136/ bmjoq-2021-001346

- Additional supplemental material is published online only. To view, please visit the journal online (http://dx.doi.org/10. 1136/bmjoq-2021-001346)

Received 12 January 2021 Accepted 24 April 2021 period.

\section{Check for updates}

(c) Author(s) (or their employer(s)) 2021. Re-use permitted under CC BY-NC. No commercial re-use. See rights and permissions. Published by BMJ.

Obstetrics \& Gynaecology, Lady Hardinge Medical College, New Delhi, India

Correspondence to

Dr Manju Puri;

drmanjupuri@gmail.com
Background Unintended pregnancies have a negative impact on the health and economy of a nation, which can be prevented by effective family planning (FP) services. Postpartum intrauterine device (PPIUCD) is a safe and effective FP method which allows women to obtain longacting contraception before discharge from the point of delivery. We observed poor coverage of deliveries with PPIUCD at our facility. This was the trigger to initiate a quality improvement (QI) initiative to increase the PPIUCD coverage from current rate of $4.5 \%-10 \%$ in 3-month

Method A fishbone analysis of the problem was done and the following causes were identified: lack of focused counselling for FP, lack of sensitisation and training of resident doctors and inconsistent supply of intrauterine contraceptive devices (IUCDs). A QI team was constituted with representatives from faculty members, residents, interns, nursing officers and FP counsellors. The point of care quality improvement methodology was used. Interventions Daily counselling of antenatal women was started by the counsellors and interns in antenatal wards. A WhatsApp group of residents was made initially to sensitise them; and later for parking of problems and trouble shooting. The residents were provided handson training at skills lab. Uninterrupted supply of IUCDs was ensured by provision of buffer stock of IUCDs with respective store keepers.

Result The PPIUCD insertion rates improved from $4.5 \%$ to $19.2 \%$ at 3 months and have been sustained to a current $30 \%-35 \%$ after $1 \frac{1}{2}$ years of initiation of the project tiding through the turbulence during the COVID-19 pandemic using QI techniques.

Conclusion Sensitisation and training of residents as well as creation of awareness among antenatal women through targeted counselling helped improve PPIUCD coverage at the facility. QI initiatives have the potential to facilitate effective implementation of the FP programmes by strategic utilisation of the resources.

\section{PROBLEM}

Unmet need of family planning (FP) in India is estimated to be $12.9 \%$ and spacing between two childbirths is less than the recommended period of 3 years in $48.1 \%$ of births. ${ }^{1}$ This unmet need is even higher in the postpartum period. ${ }^{2}$ Repeated and frequent pregnancies jeopardise the health of the women as well as their offspring. In a study on postpartum unintended pregnancies, it was found that $86 \%$ of these pregnancies were due to nonuse of contraception and more than half ended in induced abortions. ${ }^{3}$ It is estimated that use of FP methods to space births by at least 3 years can help prevent up to $30 \%$ of maternal deaths and $10 \%$ of child deaths. Despite the thrust by the Indian government in the form of incentives to the acceptors and providers of FP methods, India has yet to achieve its FP goals. ${ }^{5}$ Worldwide, long-acting reversible contraceptive methods, especially postpartum intrauterine device (PPIUCD), are being promoted in the postpartum period as they are cost-effective, safe, reliable and convenient method of contraception with no effect on lactation or sexual function. PPIUCD can be inserted within 48 hours after giving birth. Women are highly motivated and receptive to accept FP methods during the postpartum period but there is lack of focused FP counselling in the antenatal and postnatal period to make the women aware about the various contraceptive options available. Lady Hardinge Medical College and associated Shrimati Sucheta Kriplani Hospital is a busy facility located in the heart of the Indian National Capital, New Delhi and the Department of Obstetrics of this facility caters to approximately 1000 deliveries per month. However, it was observed that PPIUCD coverage of deliveries at our facility was very low (average $4.5 \%$ ) which is approximately one-fourth of the national average. While the quality improvement (QI) team understood that the heavy load and 
insufficient staff could be contributing to inadequate PPIUCD coverage, they believed that improvement in systems and processes could enhance this coverage at the facility. The FP providers are different from the ones who provide PPIUCD services, so a project to integrate both during PPIUCD insertion as a process of care (by linking FP services to labour room) was the trigger for this QI project. Our aim was to increase the percentage of deliveries covered by PPIUCD from current rate of 4.5\%-10\% in 3 months. The study population was women delivering at our hospital with no contraindications for PPIUCD insertion.

\section{BACKGROUND}

In most of the developing countries, delivery is usually the only time when healthy women seek medical attention and majority of them do not return for follow-up after delivery. Thus, the opportunity to insert a PPIUCD should not to be missed in these women while they are still at a health facility. The PPIUCD refers to the insertion of intrauterine contraceptive device (IUCD) inside the uterine cavity either immediately following delivery of the placenta or within 48 hours of delivery. In a study conducted on 372 acceptors of PPIUCD, the satisfaction rate was found to be $97.2 \%$ at the time of insertion and $95 \%$ at 6 weeks. ${ }^{6}$

The use of IUCD for contraception (both post partum and interval) among eligible women in India is very low despite being offered free of cost through the National Family Planning Programme. ${ }^{7}$ The PPIUCD coverage rate varies widely among different states in India ranging from $1.2 \%$ to $40.2 \%$ with the national average being $16.3 \% .^{89}$ Studies have implicated lack of appropriate counselling for poor acceptance of IUCD by postpartum women and focused family planning counselling (FFPC) has been shown to be effective in improving the acceptability of PPIUCD in these women. ${ }^{810}$

\section{MEASUREMENT}

An assessment of the baseline PPIUCD insertion rate was done by evaluating the statistics of preceding 2 months which revealed a total PPIUCD insertion rate of only $4.5 \%$ per month. The baseline percentage was calculated by calculating the number of PPIUCD insertions in a month divided by the total number of deliveries in that month. We decided to use the percentage of deliveries covered by PPIUCD out of the total deliveries including vaginal deliveries and caesarean section conducted in a month, as the process indicator for the project. The task of data collection was given to the auxiliary nurse midwife, posted in the FP department, who was required to collect data from the labour room and maternity operation theatre registers. The frequency of data collection was kept as weekly, followed by fortnightly and then monthly due to operational constraints.

\section{DESIGN}

A QI action team was constituted with representatives of faculty members, residents, interns, nursing officers and FP counsellors to address the problem of low PPIUCD coverage in the facility. The problem was analysed using fishbone analysis (figure 1). The following causes were identified: lack of routine counselling for FP in antenatal women due to shortage of counsellors, lack of existing departmental policy for PPIUCD, lack of sensitisation and training of residents and inconsistent supply of IUCD. To meet our target of improving the PPIUCD coverage rate, the following change ideas were implemented: daily focused FP counselling of antenatal women admitted in the hospital; sensitisation of the residents via WhatsApp groups; regular hands-on training of residents on ZOE Gynecologic Simulator (model of a full-sized, adult female abdomen and pelvis) by the consultant incharge for FP. An uninterrupted supply of IUCDs was ensured by

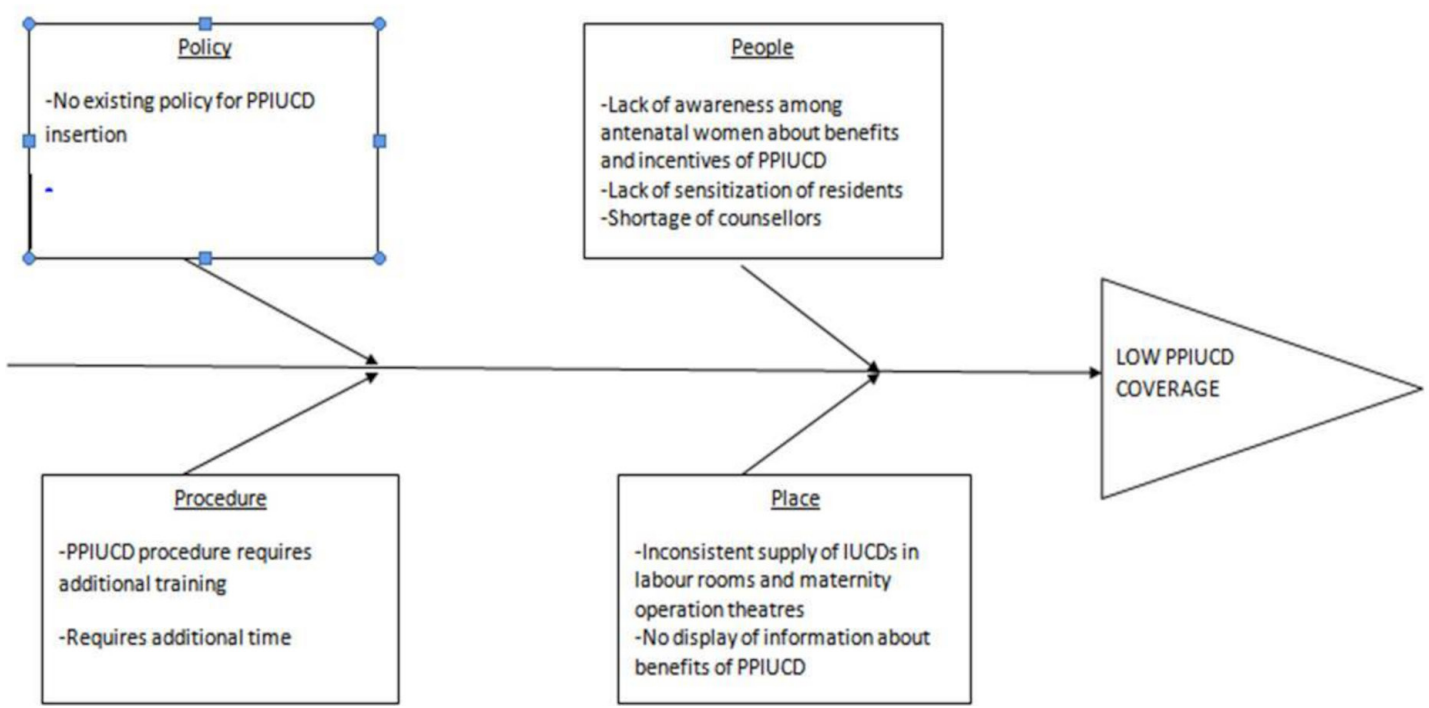

Figure 1 Fishbone analysis of the problem of low PPIUCD coverage. IUCD, intrauterine contraceptive device; PPIUCD, postpartum intrauterine device 
maintaining a buffer stock of at least 25 IUCDs in labour room and maternity OTs at all times to prevent accidental stockouts. This intervention also ensured that stocks were updated regularly and demand was raised for timely indent of IUCDs.

The study included all antenatal women delivering at our facility not having any exclusion criteria which were prolonged leaking per vaginum of more than 18 hours, any unresolved postpartum haemorrhage and diagnosed uterine malformations.

The improvement process was dynamic where the team conducted and analysed the various change ideas via multiple Plan-Do-Study-Act (PDSA) cycles. The point of care quality improvement methodology was followed. ${ }^{11}$ The team members (including representatives from faculty members, residents, nurses and interns along with FP counsellors) met weekly to investigate the progress made and identified the issues that needed to be addressed in order to achieve the desired results. The data were tabulated using the Standards for Quality Improvement Reporting Excellence guidelines. ${ }^{12}$

\section{STRATEGY}

To achieve this, we undertook five PDSA test cycles to implement our proposed interventions and another sixth one after the project completion time (3 months), when a drop in PPIUCD coverage rate was observed at the end of the fourth month. The first three PDSA cycles were done weekly to assess the feasibility of the interventions, the fourth PDSA was done at $11 \frac{1}{2}$ months, the fifth PDSA at 2 months and the additional sixth PDSA at the end of the fourth month (online supplemental table 1). The data collection were done weekly initially, followed by fortnightly, and subsequently monthly due to operational constraints.

\section{RESULTS}

Our main outcome measure was the percentage of deliveries covered by PPIUCD out of the total deliveries conducted in a month which gradually increased from $4.5 \%$ to $19.2 \%$ at the end of the 3 months. A time series chart was plotted for the collected data (figure 2). At the end of fourth month, a fall in PPIUCD coverage to $15 \%$ was observed for which an additional PDSA cycle (cycle 6) was conducted. Monthly statistics of PPIUCD insertion was shared with all faculty and residents in the monthly departmental meetings. There was progressive improvement in the PPIUCD coverage rates following this intervention till the COVID-19 pandemic arrived. During the pandemic, the wards were reorganised for COVID-19 suspects and non-suspects. Entry of counsellors to obstetric wards was restricted resulting in disruption of daily sessions of FFPC. To overcome this problem, task shifting was done and the residents posted in the obstetric wards in shift duties were entrusted with the task of FFPC in addition to their other duties. Further, the practice of sharing of monthly statistics of PPIUCD insertion in departmental monthly meetings was resumed after a short disruption due to pandemic. Since the inception of the PPIUCD QI initiative, the PPIUCD insertion rates have remained well above the proposed target of $10 \%$ in the facility. With time, the coverage of FP counselling was extended from admitted antenatal women to women visiting the outpatient department. The current PPIUCD insertion rate in our facility is above $30 \%$ which is approximately twice the national average.

It was observed that generating awareness among the eligible women is instrumental to increase the PPIUCD coverage but is not sufficient as a standalone intervention. The training and sensitisation of the caregivers is equally important. It was also realised that this training

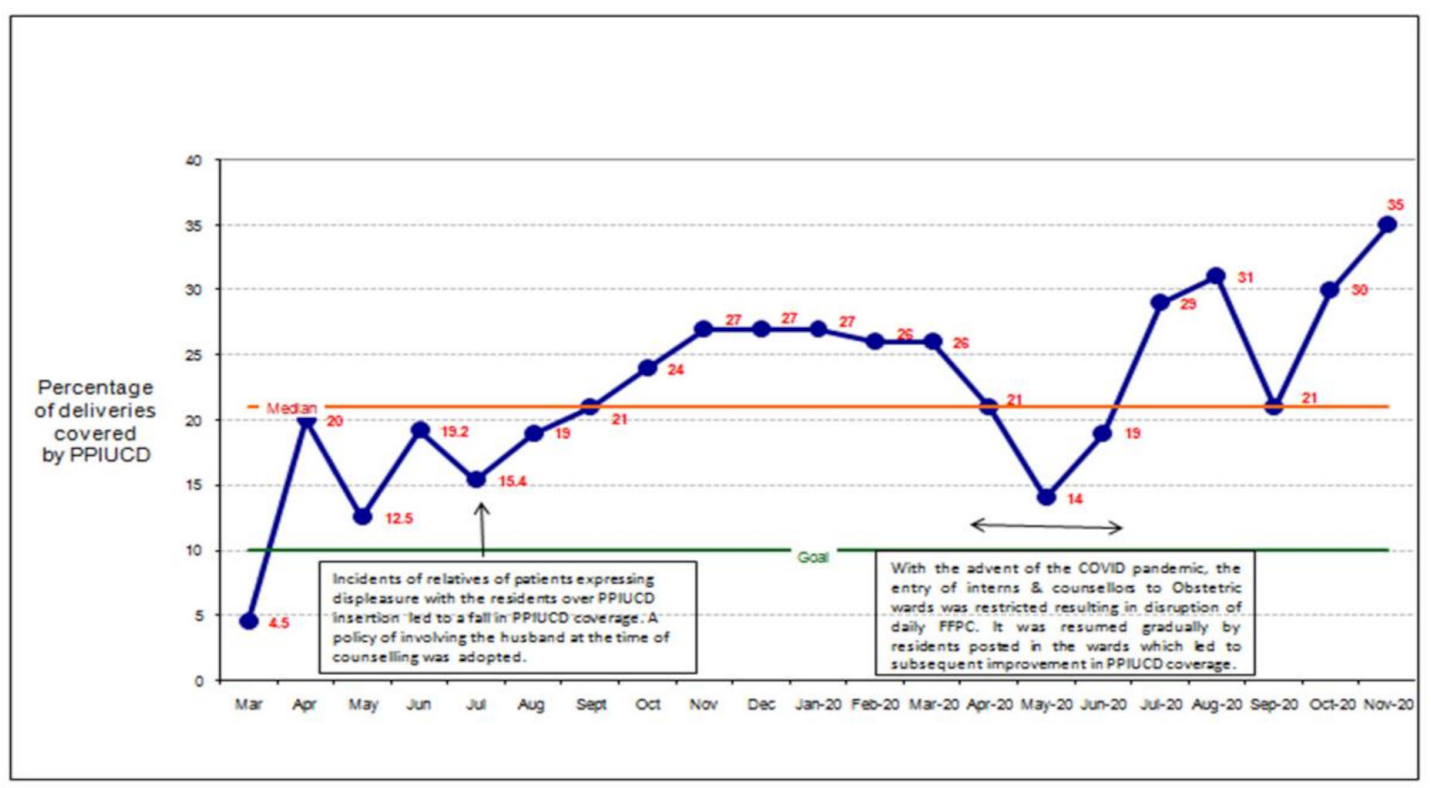

Figure 2 Time series chart of percentage of deliveries covered by PPIUCD monthly. FFPC, focused family planning counselling; PPIUCD, postpartum intrauterine device 
and sensitisation should be an ongoing process to train the residents posted on rotational basis and keep them abreast with the progress of the QI initiative. In our facility, hands-on training for PPIUCD insertion on ZOE simulator was incorporated in the induction training programme of the residents, done at the time of induction of new residents in the department. Also, the video of PPIUCD insertion was circulated every month in the dedicated WhatsApp group in order to keep everyone updated. Positive reinforcement from time to time is essential to keep up the enthusiasm of the caregivers otherwise they may lose interest.

Another significant observation was the paramount importance of communication between the team members and care providers. Regular dissemination of information to the care providers and feedback received from them through a dedicated WhatsApp group helped identify the problems at the ground level for which prompt remedial measures could be initiated by the team members. The COVID-19 pandemic taught us the importance of continuous monitoring of outcome indicators for sustenance of the initiative. Feedback was sought from the acceptors of PPIUCD by means of client exit interviews which helped to keep a check on the quality of PPIUCD service provided at the facility.

\section{DISCUSSION}

The aim of the initiative was to improve the PPIUCD coverage in the facility which would ultimately address the unmet need of contraception in the postpartum women. Multiple PDSA cycles were undertaken to bring about this change through various interventions. The key focus of all the interventions was to ensure effective and continued implementation by means of administrative support and active participation of all caregivers, to find a sustainable solution rather than a short-term gain.

\section{Strengths}

The strength of the study was that the team members ensured participation of all concerned doctors, nurses and counsellors through communication via WhatsApp groups so that a clear and uniform message was conveyed to all stakeholders and feedbacks could be collected to help the team plan further interventions based on the suggestions. The enhanced communication gave a feeling of belongingness to all concerned.

Another strength of the study was that neither any additional staff was recruited nor any additional equipment was procured. The change was brought about solely by modifying the processes of care to make the women and their caregivers enthusiastic towards PPIUCD.

\section{Limitations}

A limitation of the project was monthly analysis of the data due to manpower constraints. The authors believe that more frequent analysis of the data might have helped in preventing the intermittent reduction in PPIUCD coverage rates, as it would have led to early recognition of the underlying problem, with prompt interventions to rectify them. Another limitation of the study is that some aspects of this project like the inconsistent supply of IUCD and lack of FFPC may not be generalisable to other facilities especially in developed countries. However, we believe that the strengths of the study, such as team work, finding the root cause of problems, followed by testing and adapting different change ideas, are highly generalisable to facilities around the world.

\section{Challenges}

There were a few challenges which included the shortage of counsellors for daily FFPC. The recruitment of new counsellors would have been a time consuming and tedious process, so the idea of task shifting by training available multitasking staff and interns in FFPC proved extremely beneficial and ensured uninterrupted counselling of antenatal patients. Another challenge faced was the waning of enthusiasm among the caregivers with passage of time, which is likely to set in with long-term projects. This was addressed by recognising and rewarding the best performing caregivers to motivate the rest.

\section{Lessons learnt}

If we were to undertake this project again, we would probably start by training of the residents to make sure they were not hesitant in PPIUCD insertion. Also, the uninterrupted supply of PPIUCD would be ensured before starting FFPC so that no woman who is counselled and willing for PPIUCD is denied the benefit of PPIUCD.

Although the team was successful in achieving the target, sporadic reductions in the PPIUCD insertion rates suggest that there are still many gap areas to be plugged and more effective implementation of all the interventions is required at all levels with continuous eye on the census.

This was a novel project and a literature search has failed to reveal any QI initiative on this subject until. The authors believe that replication of the interventions suggested in the project may be beneficial to institutions having a high unmet need for contraception, especially in the postpartum period

\section{CONCLUSION}

The project team was successful in achieving a PPIUCD coverage rate of $19.2 \%$ at 3 months in the facility, which was above the national average and above the projected target of $10 \%$. All the interventions done in the project did not require any additional infrastructure or financial support. Task shifting and enhanced communication with the caregivers to instil a sense of belongingness was all that was required to achieve the desired results. The positive impact brought about by the initiative has been sustained even after $1 \frac{1}{2}$ years of its inception. However, the authors acknowledge that continued monitoring is required to ensure that this improvement is sustained. To achieve this, the project team will continue to do follow 
monthly statistics so that any deviation can be identified and addressed proactively.

Acknowledgements The authors acknowledge the hard work of all the interns, residents and nursing officers of department of Obstetrics \& Gynecology at Lady Hardinge Medical College and Smt Sucheta Kriplani Hospital, New Delhi, whose collective efforts have resulted in the success of this QI initiative.

Contributors MP, SA, AS, SuS, SS, KC, AH, AB, PL, IR, NS, PP, SW, PA, JA, SG, VS, TS, SuSa and MA all made substantial contributions to the conception or design of the work and/or the acquisition, analysis or interpretation of data for the work. SA and MP were involved in drafting the work or revising it critically for important intellectual content, and all authors were involved in final approval of this version to be published. All agree to be accountable for all aspects of the work in ensuring that questions related to the accuracy or integrity of any part of the work are appropriately investigated and resolved.

Funding The authors have not declared a specific grant for this research from any funding agency in the public, commercial or not-for-profit sectors. Publication of this article is made Open Access with funding from the Nationwide Quality of Care Network.

Competing interests None declared.

Patient consent for publication Not required.

Ethics approval This work is exempt from institutional review board review because it involved the use of existing data, documents and records. These sources are publicly available, and the information was recorded by the investigators in such a manner that subjects cannot be identified directly or through identifiers linked to the subject.

Provenance and peer review Not commissioned; externally peer reviewed.

Data availability statement All data relevant to the study are included in the article.

Supplemental material This content has been supplied by the author(s). It has not been vetted by BMJ Publishing Group Limited (BMJ) and may not have been peer-reviewed. Any opinions or recommendations discussed are solely those of the author(s) and are not endorsed by BMJ. BMJ disclaims all liability and responsibility arising from any reliance placed on the content. Where the content includes any translated material, BMJ does not warrant the accuracy and reliability of the translations (including but not limited to local regulations, clinical guidelines, terminology, drug names and drug dosages), and is not responsible for any error and/or omissions arising from translation and adaptation or otherwise.
Open access This is an open access article distributed in accordance with the Creative Commons Attribution Non Commercial (CC BY-NC 4.0) license, which permits others to distribute, remix, adapt, build upon this work non-commercially, and license their derivative works on different terms, provided the original work is properly cited, appropriate credit is given, any changes made indicated, and the use is non-commercial. See: http://creativecommons.org/licenses/by-nc/4.0/.

\section{REFERENCES}

1 National family health survey 2015-16. Available: http://rchiips.org/ NFHS/factsheet_NFHS-4.shtml

2 The Royal College of Obstetricians and Gynecologists. Best practice in postpartum family planning. best prsctice paper No. 1, 2015. Available: http://www.rcog.uk

3 Huang Y-M, Merkatz R, Kang J-Z, et al. Postpartum unintended pregnancy and contraception practice among rural-to-urban migrant women in Shanghai. Contraception 2012;86:731-8.

4 Report of a technical consultation on birth spacing, 2021. Available: https://www.who.int/maternal_child_adolescent/documents/birth_ spacing05/en/

5 Ministry of Health and Family Welfare. lucd reference manual for medical officers and nursing personnel. New Delhi, India; 2013.

6 Iftikhar PM, Shaheen N, Arora E. Efficacy and satisfaction rate in postpartum intrauterine contraceptive device insertion: a prospective study. Cureus 2019;11:e5646.

7 International Institute for Population Sciences (IIPS) and ICF. National family health survey (NFHS-4), 2015-16; 2017a.

8 Nigam A, Ahmad A, Sharma A, et al. Postpartum intrauterine device refusal in Delhi: reasons analyzed. $J$ Obstet Gynecol India 2018;68:208-13.

9 Dewan R, Bajaj B, Kapoor G, et al. Changing scenario in Indian contraceptive methods: a glimpse through a tertiary hospital statistics. J Obstet Gynecol India 2019;69:462-6.

10 Befkene Wayessa M, Workineh Abebe T, Mannekulih Habtewold $\mathrm{E}$, et al. Focused Family Planning Counseling Increases Immediate Postpartum Intrauterine Contraceptive Device Uptake: A QuasiExperimental Study]. Open Access JContracept 2020;11:91-102.

11 Srivastava S, Datta V, Garde R, et al. Development of a hub and spoke model for quality improvement in rural and urban healthcare settings in India: a pilot study. BMJ Open Quality 2020;9:e000908.

12 Goodman D, Ogrinc G, Davies L, et al. Explanation and elaboration of the Squire (standards for quality improvement reporting excellence) guidelines, V.2.0: examples of Squire elements in the healthcare improvement literature. BMJ Qual Saf 2016;25:e7. 